\title{
Elaboración de adornos sobre materiales conquiliológicos recuperados en sitios arqueológicos de la costa de Río de la Plata (ca. 3000 a 400 años AP). Aportes experimentales
}

\section{Shell adornment production in archaeological sites from the Río de la Plata coast (ca. 3000-4000 BP). An experimental approach}

\section{LAURA BEOVIDE ${ }^{1}$, MARCO LORENZO ${ }^{1} \&$ SERGIO MARTÍNEZ $^{2}$}

${ }^{1}$ Centro de Investigación Regional Arqueológica y Territorial, San José, ISJ-Dirección para el Desarrollo de la Ciencia y la Tecnología, MEC. Uruguay.

email: lbeovide@d2c2.gub.uy

${ }^{2}$ Departamento de Paleontología, Facultad de Ciencias, UdelaR, Uruguay.

email:smart@fcien.edu.uy

(Received 30 May 2018; Revised 29 June 2018; Accepted 5 October 2018)

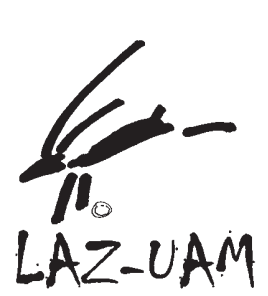

RESUMEN: En el marco del estudio de los sistemas de producción de adornos en materiales conquiliológicos identificados en sitios y colecciones arqueológicas prehispánicas del Uruguay, se analizan las técnicas de manufactura de dos conjuntos ubicados en la costa del Río de la Plata, teniendo en cuenta aportes experimentales. El primero de los conjuntos corresponde a un ajuar vinculado al enterramiento de dos niños ( $c a$. 800-400 años AP) en el que se utilizó Urosalpinx haneti (gasterópodo) como materia prima. El otro conjunto proviene de un conchero monticular (ca. 3000 a 2000 años AP) en el que se recuperaron adornos realizados sobre Erodona mactroides (bivalvo). Como resultado se clasifican los adornos como pendientes automorfos y se propone la ocurrencia de tres técnicas vinculadas a su elaboración. El abastecimiento de materia prima para la elaboración de los adornos refiere a una oferta potencial de Urosalpinx haneti localizada ca. $200 \mathrm{~km}$ y para Erodona mactroides de menos de ca. $1 \mathrm{~km}$. Se evalúan y discuten dichas estrategias de adquisición, circulación y uso como parte de la organización tecnológica vinculada al contexto arqueológico de donde provienen dichos ornamentos y la dinámica ambiental del Holoceno tardío.

PALABRAS CLAVE: ADORNOS EN CONCHAS, TECNOLOGÍA PREHISPÁNICA, SOCIEDADES DEL HOLOCENO TARDÍO
ABSTRACT: The techniques of manufacture of two sets of prehispanic shell ornaments, recovered from sites and collections of the northern coast of the Rio de la Plata (Uruguay), are analyzed through an experimental approach. The first set corresponds to a trousseau of two children (ca. 800-400 years BP), in which Urosalpinx haneti (gastropod) is used as raw material. The other set comes from the study of a shell midden ( $c a .3000$ to 2000 years BP), where ornaments made on Erodona mactroides (bivalve) were recovered. The ornaments are classified as automorphics, and the practice of three techniques associated to their elaboration is proposed. The place from where raw material was obtained for the elaboration of the ornaments was probably located at ca. $200 \mathrm{~km}$ for Urosalpinx haneti, and less than ca. $1 \mathrm{~km}$ for Erodona mactroides. 
The strategies that allowed these kinds of supply are evaluated and discussed, especially concerning their acquisition, circulation and use.

KEY WORDS: SHELLS ORNAMENTS, PREHISPANIC TECHNOLOGY, LATE HOLOCENE SOCIETIES

\section{INTRODUCCIÓN}

Las primeras señales arqueológicas de la ocupación humana de la zona costera de la margen izquierda del Río de la Plata se remontan a $c a$. 14.000 años AP (Suárez, 2017). Se vinculan con sociedades que ingresan al área en pequeños flujos de personas que, además de aprovechar los recursos terrestres de fines del Pleistoceno, supieron tener estaciones vinculadas a la explotación de los recursos acuáticos (Suárez, 2017). Testimonio de ello es el conchero de $c a$. 7000 años AP, en la costa (paleocosta) del estuario medio del Río de la Plata (Beovide et al., 2017). Los concheros en buena medida representan estrategias extraordinarias de adaptación costera reflejando la importancia de este espacio para las sociedades humanas desde épocas tempranas (Álvarez et al., 2011).

Hacia el quinto milenio antes del presente, asociado a un clima más cálido que el actual, posterior al óptimo climático, se tiene registro de sociedades ceramistas y horticultoras con distintas formas de relacionamiento con los recursos costeros del litoral Platense (Beovide, 2013b; Beovide \& Campos, 2014). Entre $c a .3000$ a 2000 años AP, se reconoce una serie de concheros, algunos monticulares, relacionados con lagunas mixohalinas (Beovide, 2011, 2013a, b). Estos concheros son producto de sociedades también horticultoras, alfareras, cuyos asentamientos se ubicaron en torno a dichas lagunas, en algunos casos transformando y demarcando el paisaje desde el punto de vista económico e ideacional, donde la actividad del marisqueo fue relevante (Beovide, 2011, 2013a, b; Beovide et al., 2017). La organización social y política se puede vincular a sociedades de rango medio (ubicadas entre bandas y sociedades estatales, Feinman \& Nietzel, 1984) que compartieron los espacios lagunares. En el contexto de los concheros formados entre $c a .3000$ a 2000 años AP (Beovide, 2011) se han identificado adornos en valvas de moluscos así como en sitios costeros estratificados del Holoceno reciente. Entre ellos, están los recuperados en la localidad arqueológica de Arazatí (Beovide et al., 2015a), asociados al momento tardío de ocupación (ca. 900 a 400 años AP).

A pesar de la identificación de adornos e instrumentos en valvas de moluscos, el estudio de los materiales conquiliológicos provenientes de sitios prehispánicos ubicados en el actual territorio uruguayo es una temática de creciente desarrollo en las últimas décadas. Sin embargo, en las regiones circunvecinas (pampeana y costa atlántica del sur de Brasil) el desarrollo ha sido más extenso y se han explorado aspectos vinculados a la gestión tecnológica, espacial y simbólica de los moluscos que hicieron las distintas sociedades holocénicas (Andrade et al., 1986; Bonomo, 2005, 2007; Rogge, 2005; Gaspar \& De Blasis, 2006; Cimino, 2007; Acosta et al., 2015, 2017; entre otros).

La identificación de instrumentos o adornos sobre valvas de moluscos en sitios arqueológicos prehistóricos fue motivo de interés para algunos de los pioneros de la arqueología en Uruguay (Seijo, 1930; Penino, 1957; Bonino, 1961). En estos últimos años, distintos investigadores han retomado la disposición por el estudio de los materiales conquiliológicos, ya sea a partir de la revisión de colecciones desde un punto de vista tecnológico (Rosa, 2011-2012) como en el marco de estudios vinculados a las sociedades constructoras de cerritos en la cuenca de la laguna Merín, los que abordan distintos aspectos de la gestión de los recursos malacológicos durante el Holoceno (Mañosa, 1995; Vi1larmarzo, 2009, 2010).

El desarrollo de programas experimentales enfocados al estudio de los procesos de manufactura de adornos en valvas de moluscos ha tenido un impulso en las últimas décadas en América Latina (Vargas et al., 1993; Velázquez et al. 2006; Velázquez, 2007, 2010; Paz, 2010; Leonardt, 2014; entre otros). En este sentido, a raíz del estudio de concheros ubicados en la costa del Río de la Plata (Beovide, 2008, 2011, 2013a, 2014; Beovide 
\& Martínez, 2014), se impulsó el análisis de los materiales conquiliógicos como parte de la organización tecnológica. También el reconocimiento de las técnicas de manufactura de distintos adornos en valvas de moluscos identificados en sitios y colecciones arqueológicas del Uruguay (Beovide \& Lorenzo, 2011, 2014; Beovide et al., 2014, 2015a, b). Estos trabajos incluyeron el desarrollo de una línea de análisis experimental de las huellas de manufactura de los adornos e instrumentos en materiales conquiliológicos, generando distintas colecciones de referencia (Beovide, 2011). Esta línea de análisis se impulsa desde el año 2006, a partir de la vinculación con el proyecto de estudio de las técnicas de manufactura de los objetos de concha en México, desarrollado en el Museo del Templo Mayor, Instituto Nacional de Antropología e Historia (INAH) de México (Velázquez, 2007).

Uno de los conjuntos de adornos en valvas de moluscos en estudio proviene de la localidad arqueológica de Arazatí ubicada a orillas del Río de la Plata en su margen izquierdo (Figura 1). Las primeras aproximaciones al registro arqueológico de dicha área se remonta a mediados del siglo XX cuando un pionero de la arqueología en Uruguay,
Raúl Penino, identifica una serie de enterramientos (Penino, 1957). Uno de ellos corresponde a un enterramiento múltiple de dos niños cubiertos con "ocre" asociado a un conjunto de adornos sobre valvas de moluscos. Los esqueletos de los niños fueron preservados en una caja de vidrio, junto con el sedimento ocre que los rodeaba y los adornos en concha, en el acervo del Departamento de Antropología Biológica de la Facultad de Humanidades y Ciencias de la Educación, Universidad de la República, Uruguay (Figura 2a).

Hacia el año 2010 se emprende la investigación arqueológica sistemática en el área de Arazatí y se aborda en paralelo la investigación de dicho enterramiento múltiple. Se determina la edad de los niños a su muerte (4 y 6 años), la composición de los sedimentos «ocre" en los que predomina la presencia de Hematita, -Fe2O3- (Beovide et al., 2015a). Los sedimentos «ocre" son asociados a formaciones geológicas del Devónico ubicadas a más de $200 \mathrm{Km}$ del lugar donde fueron enterrados los niños (Beovide et al., 2015a). En el conjunto de valvas visibles por fuera de los sedimentos se distinguieron tres tipos de adornos en Urosalpinx haneti (Tabla 1 y Figura 2b).

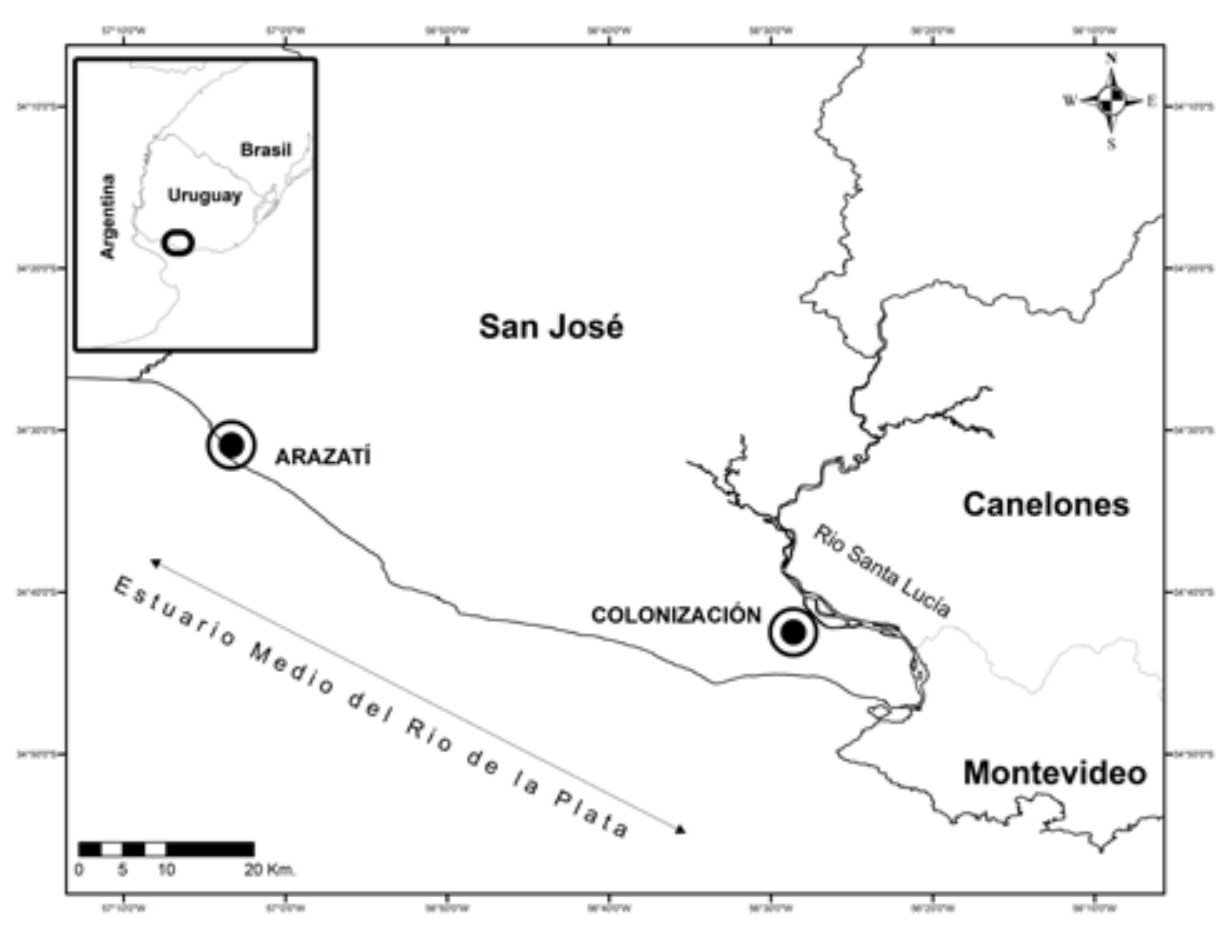

FIGURA 1

Ubicación de la localidad arqueológica de Arazatí y del conchero monticular de Colonización. 

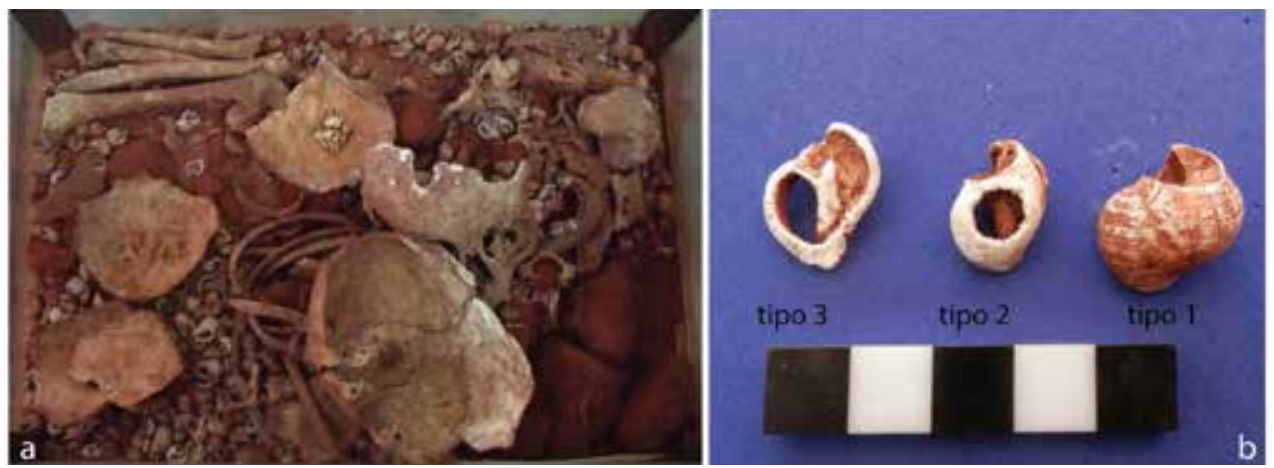

FIGURA 2

Ajuar del enterramiento múltiple de Arazatí, a) Disposición de los restos de los niños, panes de ocre y adornos en valvas de moluscos; b) tipos de adornos en Urosalpinx haneti cubiertos por ocre (escala en $\mathrm{cm}$ ).

\begin{tabular}{lcc}
\hline $\begin{array}{l}\text { Adornos en } \\
\text { Urosalpinx haneti }\end{array}$ & Características & Total \\
\hline Tipo 1 & Sin espira & $\mathbf{5 0 3}$ \\
Tipo 2 & Sin espira y con un orificio en & 363 \\
Tipo 3 & el cuerpo & 46 \\
\hline
\end{tabular}

TABLA 1

Adornos que acompañan el entierro de los niños de Arazatí. Se detallan las cantidades por tipo.

$\mathrm{Al}$ avanzar en el estudio arqueológico del área de Arazatí se postulan tres momentos de ocupación acotados por fechados ${ }^{14} \mathrm{C}$ entre $c a .4500$ y 4000 años AP, $c a .2000$ y 1000 años AP y entre 900 y 400 años AP (Beovide et al., 2015a).

Uno de los niños del enterramiento múltiple fue datado por ${ }^{14} \mathrm{C}$ AMS en $476+-30$ años AP, calibrado en 512-533 años AP (AA104638, ver Tabla 2), lo que permitió asociar dicho enterramiento al componente más tardío de ocupación (ver Tabla 2detalle de fechados del componente tardío). También se asociaron a dicho componente los adornos en Urosalpinx haneti que rodearon los niños cuya edad radiocarbónica corresponde a 895+-27 años ${ }^{14} \mathrm{C}$ AP, calibrados en 775-889 años AP (AA104637, ver Tabla 2). Cabe mencionar que $U$. haneti no se encontraría disponible en la costa de Arazatí en los últimos 2500 años, sino en la costa oceánica a más de $300 \mathrm{Km}$ de dicho lugar (Martínez et al., 2006).

Durante los trabajos de campo entre los años 2005 al 2013 en la cuenca del río Santa Lucía, tributario del río de la Plata, se identificaron una serie de concheros acotados entre los 7000 y los 2000 años AP (Beovide et al., 2017). Durante los procesos de excavación sistemática del conchero de Colonización (3000 a 2000 años AP) se identificaron adornos en valvas de Erodona mactroides (valvas con una perforación), esparcidos en distintos espacios y niveles de formación del conchero, la mayoría asociados a contextos de producción de instrumentos y adornos en distintas materias primas (conquiliológicas, líticas, dientes, Beovide, 2011). En este sentido se recuperaron junto con desechos de la talla e instrumentos líticos, cuentas elaboradas en piedras verdes (por ejemplo: malaquita), todo ello en contextos arqueológicos con evidencias de consumo de moluscos, fauna marina y terrestre, así como restos de fogones (Beovide, 2011, Beovide et al., 2017).

El objetivo del presente trabajo es explorar los procesos de producción de los adornos en Urosalpinx haneti del ajuar funerario del sitio de Arazatí (ca. 800 a 400 años AP) y los adornos con una perforación en Erodona mactroides recuperados del contexto de un conchero monticular denominado Colonización ( $c a$. 3000 a 2000 años AP). Se estudiarán como parte de la organización tecnológica (Ptaffenberger, 1988; Nelson, 1991) vinculada a las sociedades y la dinámica ambiental del Holoceno tardío para la costa del Río de la Plata. Se hará uso de la analogía experimental considerada como una heurística (Gándara, 1990) que permite generar hipótesis con las que contribuir al análisis de dichos procesos.

\section{MATERIAL Y MÉTODOS}

Para este trabajo se consideraron 503 adornos en $U$. haneti (Tabla 1) que son visibles por fuera del sedimento que cubre los esqueletos de los niños 


\begin{tabular}{|c|c|c|c|c|c|c|c|}
\hline Sitio & Exc. & Nivel & $C^{14}$ años AP & $\begin{array}{c}\text { Años Calibrados } \\
(68 \%) 1 \sigma\end{array}$ & Material/ especie & Lab./Nr. & Referencia \\
\hline Colonización & III & 7 & $2744 \pm 50(\mathrm{AMS})$ & $\begin{array}{c}2,797-2,907 \mathrm{cal} \mathrm{AP} \\
902 \pm 55 \mathrm{cal} \text { AC }\end{array}$ & $\begin{array}{c}\text { Valvas/ } \\
\text { Anomalocardia } \\
\text { brasiliana }\end{array}$ & AA/86685 & (Beovide, 2011) \\
\hline Colonización & S4 & 7 & $2716 \pm 36(\mathrm{AMS})$ & \begin{tabular}{|c|}
$2,785-2,851 \mathrm{cal}$ AP \\
$968 \pm 33 \mathrm{cal}$ AC \\
\end{tabular} & $\begin{array}{l}\text { Valva/Erodona } \\
\text { mactroides }\end{array}$ & AA/86686 & (Beovide, 2011) \\
\hline Colonización & $\mathrm{V}$ & N8 & $2699 \pm 29$ (AMS) & $\begin{array}{c}2777-2838 \mathrm{cal} \mathrm{AP} \\
858 \pm 30 \mathrm{cal} \mathrm{AC}\end{array}$ & $\begin{array}{l}\text { Erodona } \\
\text { mactroides }\end{array}$ & AA/104636 & (Beovide et al., 2014) \\
\hline Colonización & IV & 10 & $2620 \pm 50$ & $\begin{array}{l}2718-2783 \mathrm{cal} \mathrm{AP} \\
801 \pm 32 \mathrm{cal} \mathrm{AC} \\
\end{array}$ & $\begin{array}{l}\text { Valva/Erodona } \\
\text { mactroides }\end{array}$ & URU/0551 & (Beovide, 2011) \\
\hline Colonización & IV & 15 & $2600 \pm 50$ & $\begin{array}{c}2,598-2762 \mathrm{cal} \mathrm{AP} \\
730 \pm 82 \mathrm{cal} \mathrm{AC}\end{array}$ & $\begin{array}{l}\text { Valva/Erodona } \\
\text { mactroides }\end{array}$ & URU/0552 & (Beovide, 2011) \\
\hline Colonización & I & 5 & $2310 \pm 60$ & $\begin{array}{l}2211-2416 \mathrm{cal} \text { AP } \\
364 \pm 102 \mathrm{cal} \mathrm{AC}\end{array}$ & $\begin{array}{l}\text { Valva/Erodona } \\
\text { mactroides }\end{array}$ & URU/0310 & (Beovide, 2011) \\
\hline Arazatí (Tardío) & II & 5 & $507+-32$ (AMS ) & $\begin{array}{c}1416+-13 \mathrm{cal} \mathrm{AD} \\
521-547 \mathrm{cal} \text { AP }\end{array}$ & Cerámica & $\begin{array}{l}\text { AA104640 } \\
\text { X28071 }\end{array}$ & (Beovide et al., 2015a) \\
\hline Arazatí (Tardío) & II & 7 & $827+-25$ (AMS) & $\begin{array}{c}1212+-27 \mathrm{cal} A D \\
711-765 \mathrm{cal} A P\end{array}$ & Cerámica & $\begin{array}{l}\text { AA105992 } \\
\text { X28776L }\end{array}$ & (Beovide et al., 2015a) \\
\hline Arazatí (Tardío) & \multicolumn{2}{|c|}{ Enterramiento múltiple, niños } & $476+-30$ (AMS) & \begin{tabular}{|c|}
$1427+-10 \mathrm{cal} \mathrm{AD}$ \\
$512-533 \mathrm{cal} \mathrm{AP}$ \\
\end{tabular} & Óseo Humano & $\begin{array}{c}\text { AA104638 } \\
\text { X28069 }\end{array}$ & (Beovide et al., 2015a) \\
\hline Arazatí (Tardío) & \multicolumn{2}{|c|}{$\begin{array}{l}\text { Adorno del ajuar del } \\
\text { enterramiento múltiple }\end{array}$} & $895+-27$ (AMS) & $\begin{array}{c}1118+-57 \mathrm{cal} \mathrm{AD} \\
775-889 \mathrm{cal} \mathrm{AP}\end{array}$ & $\begin{array}{c}\text { Valva/Urosalpinx } \\
\text { haneti }\end{array}$ & $\begin{array}{l}\text { AA104637 } \\
\text { X28068 }\end{array}$ & (Beovide et al., 2015a) \\
\hline
\end{tabular}

TABLA 2

Cuadro fechados radiocarbónicos. Localidad Arqueológica de Arazatí fechados componente tardío. Conchero del sitio Colonización fechados ca. 3000 a 2000 años AP.

prehispánicos de Arazatí. U. haneti (Petit de la Saussaye, 1856) (Gastropoda, Muricidae) es una especie de gasterópodo marino que mide hasta aproximadamente $3 \mathrm{~cm}$ de largo, de clima templado, endémica de la Provincia Argentina, que vive en sustratos consolidados (o en micro sustratos duros sobre fondos de conchilla, arenosos o fangosos) desde el submareal hasta los $20 \mathrm{~m}$ (Figura 3a) (Costa, 1993; Ríos, 1994, Scarabino et al., 2006a). Como fósil se lo ha reconocido en las cercanías de Piriápolis, en un yacimiento de $2490+/-70$ años ${ }^{14} \mathrm{C}$ (Martínez et al., 2006), calibrado en 1957-2314 años AP (2 sigma) (Martínez \& Rojas, 2013).
El segundo conjunto de adornos considerado fue elaborado sobre valvas de Erodona mactroides Bosc, 1801 (Bivalvia, Erodonidae) que presentan una perforación, recuperadas en el conchero monticular de Colonización (ca. 3000 a 2000 AP, ver Tabla 1), en la cuenca baja del río Santa Lucía, tributario del Río de la Plata (Figura 2b) (Beovide, 2011; Beovide \& Martínez, 2014; Beovide et al., 2015b).

Erodona mactroides es un bivalvo de ambiente estuarino, con un tamaño de 3 a $4 \mathrm{~cm}$, que vive en sustratos arenosos y fangosos (ver Figura 3b) (Carcelles, 1941; Da Costa, 1971; Scarabino et al.,
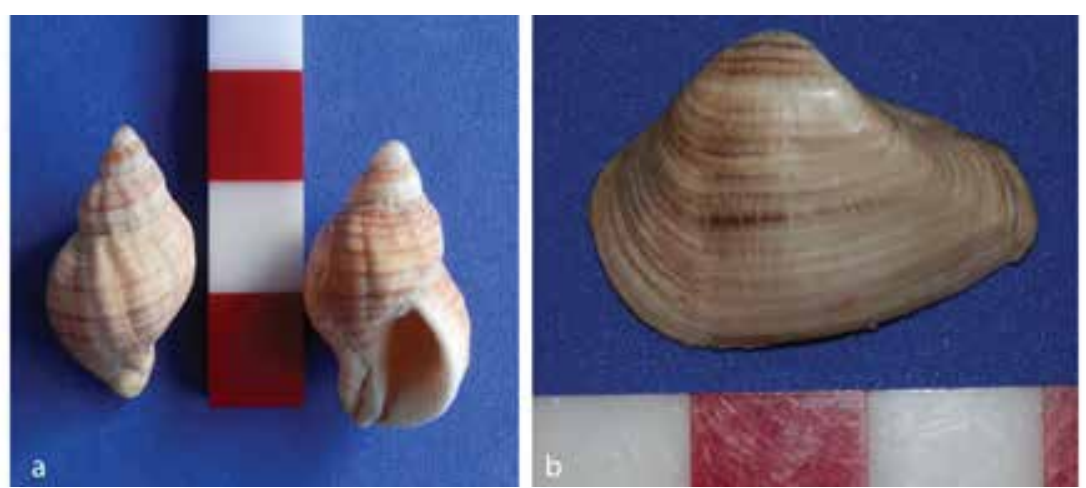

FIGURA 3

A) Urosalpinx haneti; b) Erodona mactroides. Escala en $\mathrm{cm}$. 
2006b). Se lo puede reconocer en la costa del Río de la Plata y en las lagunas asociadas. Es un molusco comestible pudiendo ser recolectado a lo largo de todo el año, hecho que es realizado actualmente por algunas comunidades de pescadores artesanales (Beovide, 2014).

Como primer paso para el análisis de los conjuntos de adornos sobre Urosalpinx haneti y Erodona mactroides en el marco de la organización tecnológica (Nelson, 1991; Ptaffenberger, 1988) se observaron las modificaciones que presentan las valvas de moluscos en relación con las características que definen a ambas especies, tanto a simple vista como a bajos aumentos. Para esto último se utilizó una lupa binocular (NIKON SM 2800) y Lupa digital, Vktech ${ }^{\circledR}$ Plegable 500x, 5MP. Para las piezas arqueológicas se tomó en cuenta el estado de deterioro de las valvas en base a los 6 grados establecidos por Dirrigl (1995; citado por Claassen, 1998: 67) y adaptados a las especies consideradas (Beovide, 2011; Beovide et al., 2015b).

En una segunda instancia se clasificaron los adornos teniendo en cuenta la magnitud de transformación sufrida en el exoesqueleto en la medida que permite o no reconocer la especie de molusco. Luego se clasifican teniendo en cuenta el tipo de adorno producido según los trabajos de Suárez (1974, 1977) y Velázquez (2007) y la tipología propuesta por dichos autores (cuentas, pendientes, entre otros).

El análisis se complementó generando una colección de adornos en concha experimentales con las cuales comparar gestos técnicos y huellas de manufactura en cada tipo de materia prima (Urosalpinx haneti y Erodona mactroides). Para sistematizar los experimentos se consideró la metodología propuesta por Velázquez (2007). En este sentido, se consideraron los siguientes aspectos para cada experimento: número, fecha y nombre, objetivo (en este caso, reproducir el adorno), materiales a utilizar, descripción de los materiales (percutor, perforador etc.), descripción de los procedimientos (descripción de la técnica), hora de inicio, hora de finalización y descripción del resultado. Cabe agregar que para la elaboración de los adornos se usaron réplicas de los tipos de instrumentos recuperados en los contextos arqueológicos de los cuales provienen los adornos a reproducir.

Para realizar las réplicas experimentales se seleccionaron rasgos recurrentes y observables a simple vista identificados en cada uno de los con- juntos de adornos, como la ausencia de ápice, espira, la presencia de orificios, o el desgaste de una de las caras. Los adornos arqueológicos también se observaron a bajos aumentos (10X a 40X), con el fin de identificar rasgos que posteriormente pudieran estar presentes al estudiar las réplicas. Para el análisis se hizo uso de los antecedentes bibliográficos en cuanto a las huellas que deja el emplear determinadas técnicas (Velázquez, 2007, 2010) y la experiencia que se ha obtenido con el trabajo experimental con otras especies.

La discusión de los resultados, en el marco de la organización tecnológica, tuvo en cuenta aspectos paleogeográficos de las especies y la ubicación y características de los sitios arqueológicos.

\section{RESULTADOS}

Los adornos vinculados al ajuar elaborado sobre Urosalpinx haneti (todos ellos cubiertos de ocre -hematita-, Beovide et al., 2015a) fueron clasificados como pendientes automorfos. La categoría de pendientes se definió siguiendo los criterios de Suárez $(1974,1977)$ en el que la concha, tanto de gasterópodo como de bivalvo, presenta una o varias perforaciones localizadas en algún extremo de la pieza, que puede o no presentar simetría respecto de la perforación. Se clasificaron como automorfos puesto que en los adornos puede ser reconocida la forma original de la valva. El estado de conservación de las piezas arqueológicas se clasifica en general en un estadio 3, en el que las valvas presentan un primer estado de intemperismo y aún conservan su estructura, sin ser porosa la superficie.

De los 503 adornos de $U$. haneti analizados, 363 (tipo 1, Tabla 1) son clasificados como pendientes automorfos con un solo orificio derivado de la ausencia de la espira (Figura 2b).

En la Figura 4a se presentan los instrumentos utilizados en el diseño experimental para comprender las huellas y gestos posibles de manufactura de los pendientes tipo 1. En las Figuras 4b-c se expone el proceso que consistió en desgastar por fricción el contorno de la sutura entre la espira y la última vuelta con un instrumento de caliza silicificada y terminar de suprimir la misma mediante percusión directa usando un percutor de anfibolita con apoyo de un yunque. Ambas materias primas se encuentran en el contexto arqueológico asociado a 

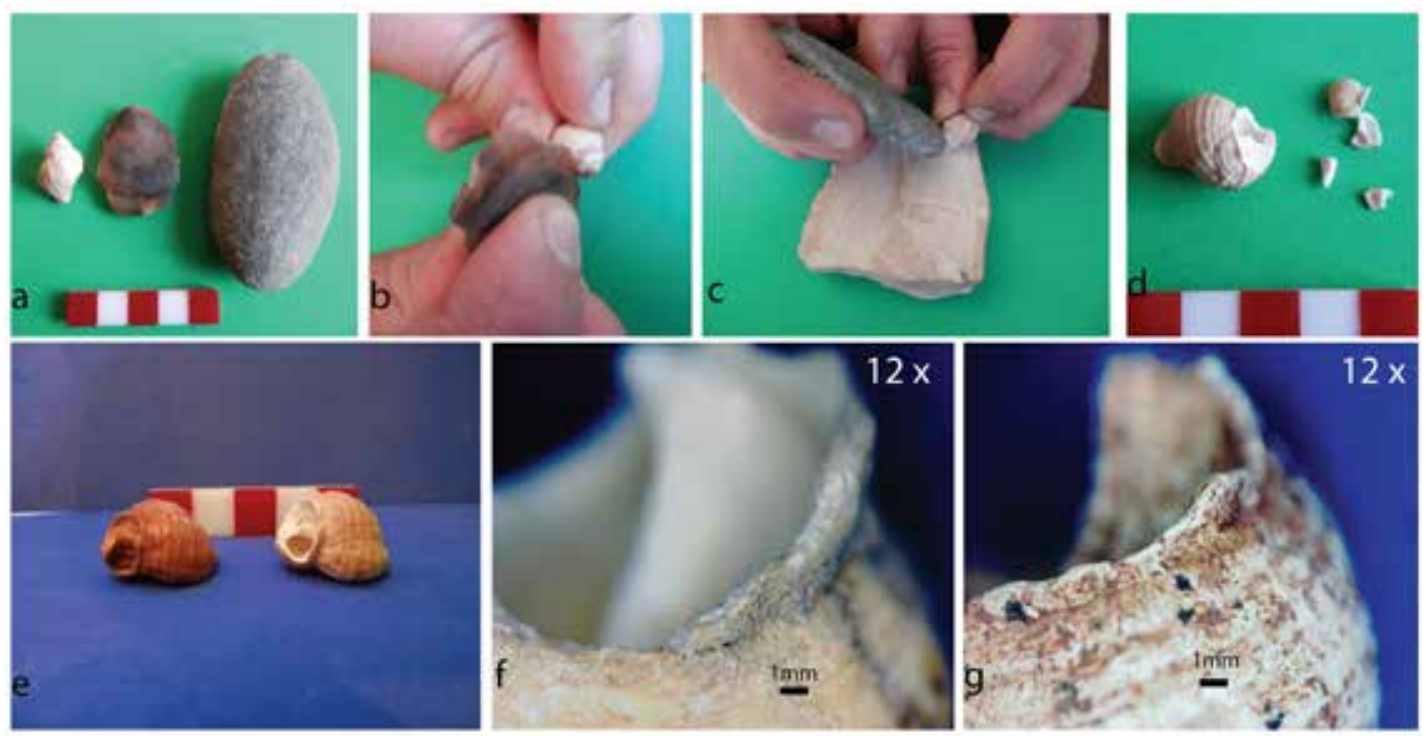

FIGURA 4

Proceso de elaboración del pendiente tipo 1 en Urosalpinx haneti. a) materiales utilizados (U. haneti, instrumento en caliza silicificada y percutor de anfibolita) sumado al yunque de la imagen c. b) demarcado de una línea de corte en la sutura de la espira y la última vuelta. c) percusión con apoyo de yunque. d) resultado: pieza con ápice fracturado y desechos. e) imagen de pieza arqueológica a la izquierda y a la derecha pieza experimental. f) detalle del borde irregular de la pieza experimental resultado de la percusión para retirar el ápice. g) detalle del borde irregular sin ápice en la pieza arqueológica; en ésta se observan las manchas de ocre que impregna la superficie del gasterópodo.

los adornos. Se realizó un experimento exitoso que duró 16 minutos y se registraron cuatro fragmentos irregulares de la fractura de la espira (Figura 4d). La combinación de ambas técnicas, desgaste y percusión, es la que deja un borde irregular con bordes suavizados, comparable con los bordes identificados en los pendientes arqueológicos y mencionado en trabajos referentes (Velázquez, 2007, ver Figura 4). Se propone entonces que el pendiente es elaborado por la combinación de dos técnicas: desgaste por fricción y percusión directa.

Los siguientes 46 adornos se clasifican también como pendientes automorfos con dos perforaciones realizados sobre $U$. haneti (Tipo 2, Figura 2b, Tabla 1). Uno de los orificios resulta de la ausencia de la espira y el segundo corresponde a una perforación realizada en la última vuelta de la conchilla (Figura 2b). Se realizó la réplica experimental mediante un experimento exitoso. En la Figura 5a y c se detallan los materiales e instrumentos utilizados (U. haneti, un instrumento de caliza silicificada, percutor de anfibolita, fragmento de arenisca y perforador de caliza silicificada). La espira se retiró marcando primero por desgaste de fricción la sutura entre la espira y la última vuelta, y luego se percutió con el apoyo de un yunque (Figura $5 \mathrm{~b}$ y c).

Archaeofauna 28 (2019): 141-156
La segunda perforación se encuentra en la última vuelta de la conchilla y tienen de 4 a $7 \mathrm{~mm}$ de diámetro promedio (Figura $5 \mathrm{~g}$ ). En el experimento (Figura 5d) se perforó el cuerpo de $U$. haneti mediante la técnica de desgaste por fricción (fragmento de arenisca) y luego se terminó de perforar por desgaste por rotación alterna con perforador de caliza silicificada (Figura 5e). Como resultado de todo el proceso, se replicó el pendiente y se registró una serie de desechos irregulares (20 fragmentos entre $1 \mathrm{~mm}$ a $5 \mathrm{~mm}$ de diámetro, Figura 5f). La comparación de ambas piezas, experimental y arqueológica se expone en la Figura 5g. En la Figura $5 \mathrm{~g}$ se muestra el adorno experimental y el arqueológico. Se observan a 40x las huellas del desgaste (rayones y líneas finas) orientadas en ambas piezas en el sentido del desgaste (Figuras $5 \mathrm{~h}$ e i). En la pieza arqueológica (Figura 5i) se puede observar el efecto erosivo natural de la superficie de la valva por haber estado enterrada y la presencia del sedimento ocre.

Se replicó experimentalmente el pendiente tipo 3 que se caracteriza por el desgaste del cuerpo y la falta de la espira. Se registran 94 piezas arqueológicas clasificadas como pendientes automorfos del tipo mencionado. La réplica experimental del pendiente con dos perforaciones en el exoesqueleto 

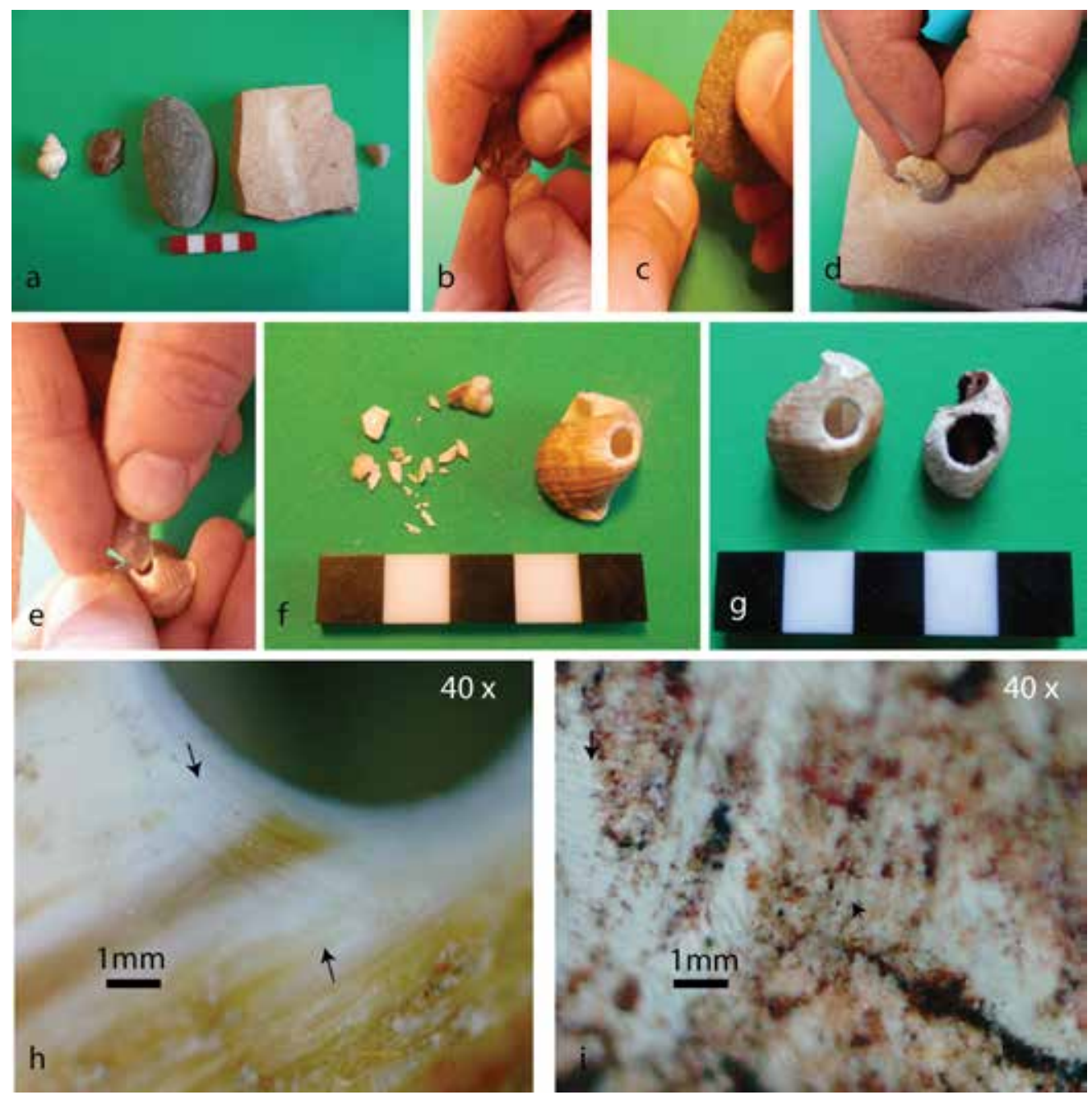

FIGURA 5

Experimentación y comparación de pendiente arqueológico y experimental con dos orificios (Tipo 2). a) materiales utilizados en la experimentación (Urosalpinx haneti, instrumento en caliza silicificada, percutor en anfibolita, fragmento de arenisca, y perforador en caliza silicificada). b) demarcación de la espira con instrumento de caliza silicificada. c) percusión directa sobre la espira. d) desgaste de la superficie sobre el fragmento de arenisca. e) desgaste por rotación alterna. f) resultado de la experimentación (pieza, y 20 fragmentos) escala en $\mathrm{cm}$. g) comparación de la pieza experimental -izquierda- con la arqueológica -derecha-, escala en $\mathrm{cm}$. h) detalle del borde del orificio sobre el cuerpo señalando las huellas del desgaste en dos sentidos, 40X. i) detalle de las huellas en la pieza arqueológica donde se observan también los granos de ocre.

de $U$. haneti implicó un experimento exitoso que duró 32 minutos (Figuras 6e y f). En la Figura 6 se muestra el proceso de manufactura de pendiente tipo 3. Se exponen los materiales con los que se realizó la réplica experimental (U. haneti, percutor en anfibolita y fragmento de arenisca) (Figura 6a). Primeramente se retira la espira por percusión directa con apoyo en yunque (Figura 6b). Se fricciona sobre un fragmento de arenisca el cuerpo de la valva (Figura 6c). Se produce el degaste de la superficie de la valva (Figura 6d, resultado: pieza desgastada, espira fracturada y resto del mismo como único desecho, Figura 6e, comparación de piezas -izquierda: experimental, derecha: arqueológica), Figura 6f, huellas de fricción (líneas finas y rayones orientados en sentido del desgaste) sobre la superficie de la valva experimental, Figura $6 g$, huellas de fricción sobre la valva arqueológica y restos de ocre sobre la superficie.

Los 32 adornos identificados en el Conchero de Colonización elaborados sobre valvas de Erodona 

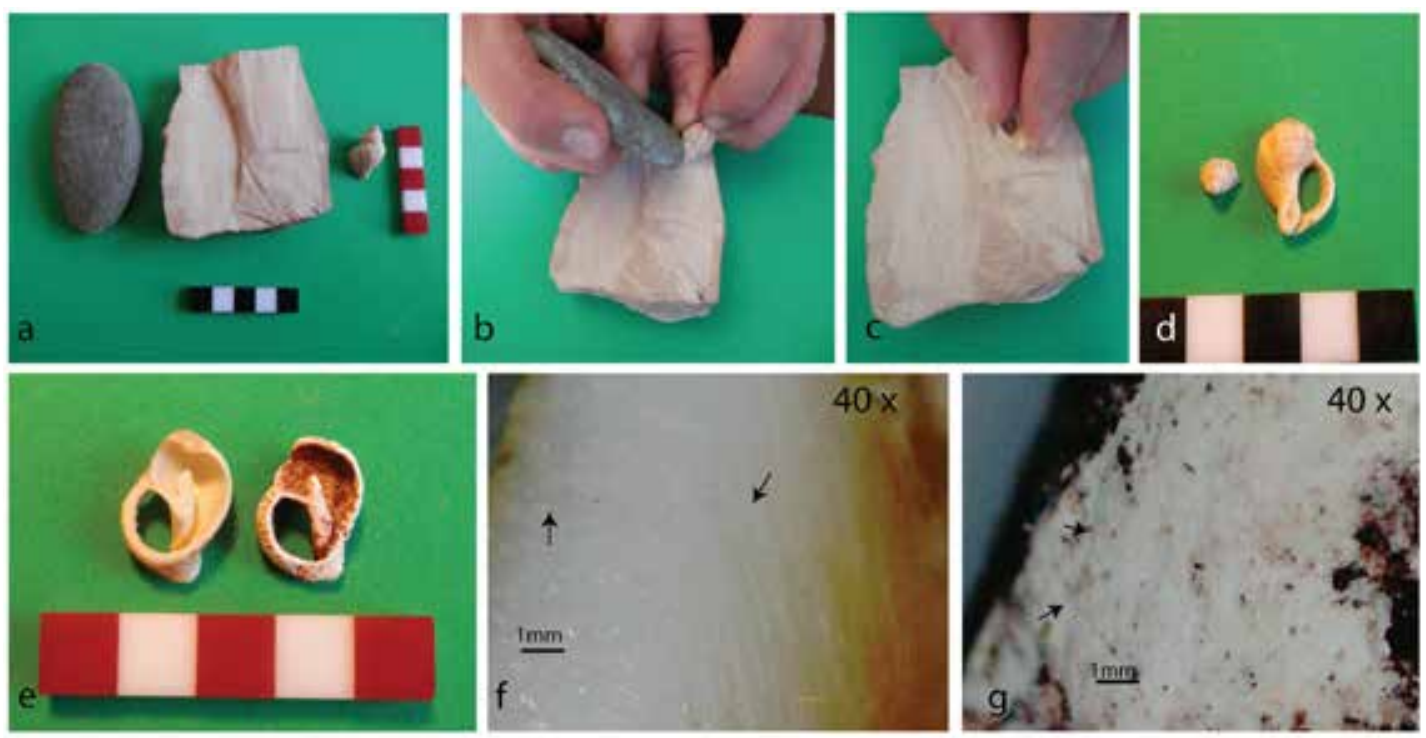

FIGURA 6

Proceso de manufactura de pendiente tipo 3. a) materiales con los que se realizó la réplica experimental (Urosalpinx haneti, percutor en anfibolita y fragmento de arenisca). b) retiro de la espira por percusión directa con apoyo en yunque. c) fricción sobre arenisca de la valva. d) resultado: pieza desgastada, espira fracturada y resto de la misma como único desecho. e) comparación de piezas -izquierda: experimental, derecha: arqueológica). f) huellas de fricción sobre la superficie de la valva experimental. g) huellas de fricción sobre la valva arqueológica, se observan restos de ocre sobre la superficie.

mactroides se clasifican como pendientes automorfos. Todos ellos presentan un solo orificio, irregular, ubicado en el área del umbo o un poco por debajo hacia la región ventral, con diámetro promedio de $5 \mathrm{~mm}$ (Figuras 7a y 8a). La mayoría de las perforaciones se ubican sobre la valva derecha $(n=19$, $59 \%$ ). Todas las perforaciones se propone fueron realizadas usando la técnica de desgaste. En 18 de los pendientes se utilizó la técnica del desgaste por fricción para realizar la perforación (Figura $6 \mathrm{~b}$ y c), en 10 se perforó por desgaste por rotación alterna desde la cara externa de la valva y en 4 desde la cara interna de la misma.

La Figura 7a muestra uno de los pendientes arqueológicos elaborados sobre E. mactroides. Este pendiente fue elaborado por fricción desde la cara externa (Figura 7b y c). Se expone la experimentación realizada a partir de friccionar con un instrumento de caliza silicificada la cara externa de la valva (Figura 7d). El tiempo para producir el orificio fue de una hora, tiempo que duró un único experimento, exitoso. En la Figura 7e se observa a bajos aumentos la superficie externa de la valva experimental en comparación con la arqueológica (Figura 7f). Se observa un área de desgaste bordeando el orificio logrado con la técnica de fricción compatible con las huellas de desgaste que presenta la muestra arqueológica. En las Figuras $7 \mathrm{~g}$ se muestra las cara interna del pendiente experimental y el arqueológico en la Figura 7h, se observa a bajos aumentos la huella circular producto que se origina como respuesta a la fricción por cara externa.

En la Figura 8a muestra el pendiente arqueológico sobre E. mactroides cuya perforación fue hecha por la técnica de desgaste por rotación alterna; en la Figura 8b se muestra el gesto técnico vinculado a la perforación alterna realizada con un instrumento de cuarzo y en $8 \mathrm{c}$ se muestra el resultado de la perforación experimental. Se realizó un solo experimento exitoso, logrando el pendiente en 2 minutos.

Ambas perforaciones arqueológica y experimental muestran bordes irregulares con una huella de desprendimiento de la superficie externa de la valva de forma circular que surge del proceso de desgaste por rotación alterna (Figuras $8 \mathrm{~d}$ y e). En la cara interna también se pueden apreciar distintas marcas de desgaste en el sentido de la rotación sobre la superficie de la valva (Figuras $8 \mathrm{f} \mathrm{y} \mathrm{g).} \mathrm{Si} \mathrm{la}$ valva es horadada desde la cara externa, se produce también un negativo circular en torno al orificio pero se ubica en la cara interna y el tiempo que lleva realizarlo es de 20 minutos. 

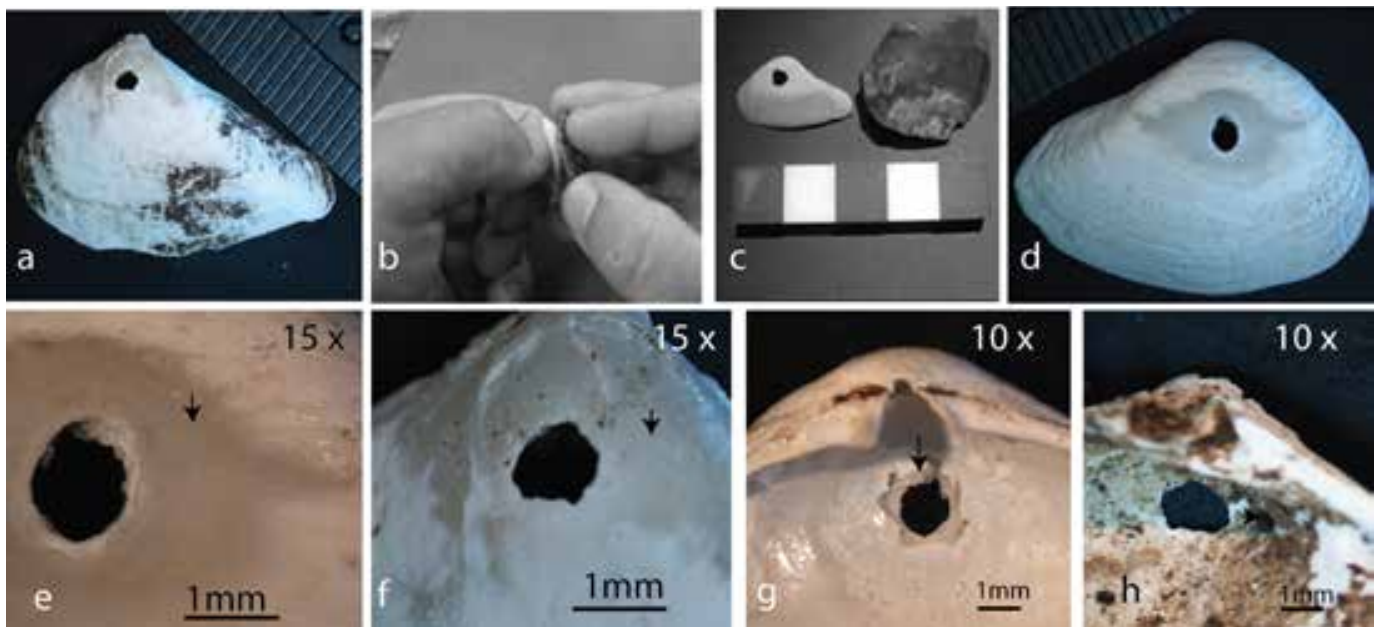

FIGURA 7

Pendiente automorfo en Erodona mactroides. a) Pendiente arqueológico, escala en mm. b) desgaste por fricción experimental sobre valva de E. mactroides. c) pendiente resultante por la acción de friccionar sobre la superficie de la valva con instrumento de caliza silicificada, escala en $\mathrm{cm}$. d) pendiente experimental escala en $\mathrm{mm}$. e) huella de desgaste bordeando orificio en superficie externa de valva experimental (15X). f) huella de desgaste bordeando orificio en superficie externa de valva arqueológica (15X). g) huella circular de fractura bordeando el orificio cara interna de valva experimental (10X). h) huella circular de fractura bordeando el orificio cara interna de valva arqueológica.

\section{DISCUSIÓN}

En cuanto al trabajo experimental que recrea las técnicas usadas para elaborar los orificios en Erodona mactroides, se identificaron dos técnicas de desgaste: por fricción y por rotación alterna. Las huellas son comparables con las identificadas en los pendientes arqueológicos (lascado circular, líneas y orientación de las mismas asociadas al borde del orificio). En estudios previos de este conjunto de adornos se valoraron las diferencias entre los orificios naturales y los producidos por acciones antrópicas vinculadas al tipo de borde (tamaño, forma, orientación del eje, entre otras variables), así como la morfología y ubicación de las modificaciones de superficie junto con la distinción entre líneas de corte, raspado o fricción (Beovide, 2011; Beovide \& Lorenzo, 2011; Beovide et al., 2015b).

Con relación a los aportes experimentales relacionados con los tipos de adornos en $U$. haneti, las huellas vinculadas a la eliminación de la espira son reconocidas a simple vista por sus bordes irregulares y comparables no solo con los arqueológicos propios sino con la bibliografía de referencia (Velázquez, 2007). Los orificios producidos por desgaste de forma experimental presentan huellas según la técnica empleada (desgaste por fricción y rotación alterna) cuya forma, ubicación y orien- tación también es comparable con los ejemplares arqueológicos analizados y con la bibliografía de referencia (p. e. Velázquez, 2007). Los muestreos (de $1 \times 1 \mathrm{~m})$ realizados en este estudio con el fin de obtener ejemplares $U$. haneti-cuyas conchillas son particularmente gruesas- en playas oceánicas de Uruguay no identificaron ejemplares con la falta de espira o presencia de orificios, así como tampoco se registran en los muestreos de depósitos fósiles del Holoceno (Martínez et al., 2006). Si bien aún hay mucho por hacer en el estudio tafonómico de $U$. haneti, las huellas identificadas en los más de 500 ejemplares y su comparación con los estudios experimentales son un primer inicio en la distinción entre marcas naturales y antrópicas para dicha especie.

En cuanto al análisis de la organización tecnológica vinculada a las especies estudiadas, el bivalvo Erodona mactroides se encontraría disponible como materia prima en el fondo de las aguas someras de las lagunas lindantes al conchero de Colonización ( $c a .3000$ a 2000 años AP, Beovide, 2011). La recolección de moluscos vivos con fines alimenticios podría ser uno de los mecanismos usados para el abastecimiento de las valvas usadas como materia prima para la elaboración de los adornos. Después del consumo, las valvas descartadas pueden ser utilizadas con fines tecnológicos. Alternativamente, las valvas pueden haber sido recolectadas en los depósitos de conchilla que 
se encuentran en los márgenes de las lagunas (hoy paleolagunas) asociadas a los sitios arqueológicos. Los instrumentos con los cuales trabajar la valva se encuentran en los contextos asociados a los pendientes. Se identificaron perforadores en cuarzo y caliza silicificada, yunques y percutores en granito, arenisca y anfibolita. Del conchero monticular de Colonización, además de los pendientes analizados, se recuperaron adornos en piedras verdes y en dientes de tiburón (de tres especies de Condrictios, Beovide, 2011). La materia prima está disponible en un radio de menos de $1 \mathrm{~km}$ y la elaboración del pendiente se realizó en el área del conchero, registrándose desechos de la talla y de perforaciones fallidas (Beovide, 2011; Beovide \& Lorenzo, 2011).

Se ha propuesto que los concheros son producto de múltiples actividades (Gaspar, 1998). Estos pueden referenciar aspectos vinculados a la habitación, la alimentación, los festejos, la producción y la funebria como parte de la cotidianeidad de los grupos. La producción de los adornos en concha identificados como pendientes automorfos en el sitio Colonización parece estar contenida en actividades referidas al adorno personal, como elementos no utilitarios de carácter simbólico y vehículos de comunicación (Suárez, 1998; Trubbit, 2003; entre otros).

A principios del siglo $\mathrm{XX}$ sobre los grupos Yamana, Martín Gusinde, describe que para confeccionar los adornos "recogen conchas, del tamaño de un garbanzo,... cerca del borde exterior se practica una pequeña perforación frotando la concha del caracol sobre una piedra áspera" (Gusinde, 1987: 420). La elaboración del adorno en los lugares cercanos a su recolección costera se proyecta como imagen de las actividades probables llevadas a cabo en el área del conchero de Colonización, en la que también se elaboraron pendientes por la técnica de desgaste por fricción.

Hacia el Holoceno tardío comienzan a delinearse los actuales humedales del río Santa Lucía y de la costa del Río de la Plata, y se relacionan con sociedades horticultoras alfareras que aprovecharon los recursos de las tierras bajas en su particularidad, e inmersas en un marco de redes de interacciones regionales como parte de una larga trayectoria originada a fines del Pleistoceno (Beovide, 2013b). La producción de cerámica, el hilado, la producción de instrumentos y alimentos de forma sistematizada, contextualiza las sociedades que dieron lugar a la elaboración de los pendientes de valvas de Arazatí (Beovide, 2013b). El proce- so de producción de pendientes, en el caso de los adornos vinculados al ajuar de los niños de Arazatí, implicó la obtención de la materia prima en las zonas costeras vinculadas a ambientes marinos (costa Atlántica de Uruguay o Argentina, en un radio de más de $200 \mathrm{~km}$ del enterramiento). En este sentido la especie $U$. haneti no estaría disponible en la zona costera Platense hacia $c a .1000$ años AP, y la disponibilidad como subfósil en el área del Río de la Plata se referencia en $c a .2500$ años AP (Martínez \& Rojas, 2013). Tomando en sentido literal los fechados y considerando que para la costa uruguaya el efecto reservorio ha sido valorado como no significativo (Bracco et al., 1999), los adornos pueden haber sido elaborados más de 300 años antes (los adornos datan de $c a .800$ años AP y los enterramientos $c a$. 500 años AP, Beovide et al., 2015a). Sin embargo, no se puede descartar que hayan sido manufacturados hacia el momento de muerte de los niños, ya que se ha observado que en general los exoesqueletos de los moluscos pueden permanecer más de 500 años en las playas (ver discusión en Martínez \& Rojas, 2013). Otra posibilidad es que la materia prima haya sido obtenida y luego almacenada para la futura elaboración de adornos, lo que podría indicar la especialización en la producción. Los procesos de elaboración de los tres tipos de pendientes en el conjunto de 503 ejemplares implicaron varias técnicas (percusión, desgaste alterno y fricción). Sin sumar el tiempo y traslado para adquirir la materia prima (que según las distancias y el tipo de transporte puede ser de un día a varios), los pendientes que presentaron la combinación de dos técnicas pueden haber implicado media hora promedio de trabajo (según los resultados experimentales presentados) y aquellos elaborados por percusión de menos de tres minutos. Se podría pensar que todo el conjunto pudo ser elaborado en un tiempo aproximado de 88 horas o sea unos cuatro días, si trabajara una sola persona todo el tiempo (lo anterior puede variar a menos días si son varias personas que trabajan, y más días si ponderamos el tiempo de descanso). Todo lo anterior habla de la complejidad de la elaboración del conjunto de adornos identificados por fuera de los sedimentos y de la preparación de los entierros.

En general, los adornos en $U$. haneti se reconocen en sitios del Paraná Inferior y la región pampena para el Holoceno tardío (Bonomo, 2005, 2007; Acosta et al., 2015, 2017; Figura 8). Por ejemplo, para el sitio Arroyo Sarandí (Figura 8) se menciona el enterramiento de un individuo femenino con 

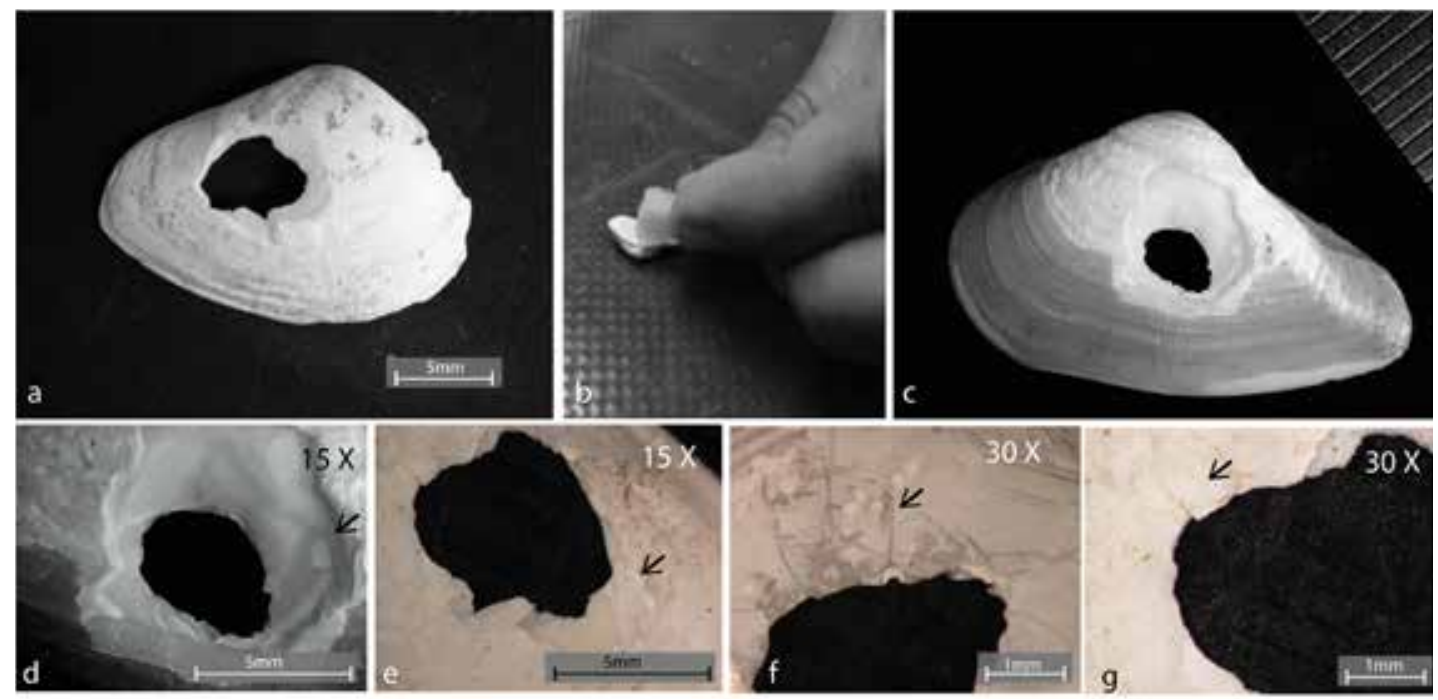

FIGURA 8

Proceso de elaboración de pendiente automorfo en Erodona mactroides. a) pendiente arqueológico. b) desgaste por rotación alterna desde cara interna sobre valva de E. mactroides. c) pendiente experimental resultante. d) detalle del orificio experimental con lascado circular en cara externa. e) detalle del orificio arqueológico con lascado circular en cara externa. f) detalle de marcas en cara interna contra el borde producto de la rotación alterna. g) detalle de marcas en cara interna de la valva arqueológica contra el borde.

pendientes ubicados en el área del cuello elaborados sobre $U$. haneti (Lothrop, 1932: 177), asociado a un fechado de $1290 \pm 40$ años AP (Acosta et al., 2015, 2017). Según la descripción, la ausencia de espiras en los 209 ejemplares allí registrados podría indicar el uso de técnicas similares a las descriptas para el ajuar de los niños. En este sentido, se ha propuesto que $U$. haneti pudo haber sido especialmente elegida en los ajuares funerarios de la región (Acosta et al., 2017). Se ha asociado el enterramiento de los niños de Arazatí con sociedades ceramistas-pescadoras-horticultoras del Holoceno tardío (con presencia de Zea mays) que se asentaron en aldeas vinculadas con humedales. La especialización (Clark \& Parry, 1990; Velázquez, 2007) en la producción de objetos en concha se puede apreciar en el proceso de elaboración de los adornos que va desde la elección de la materia prima, la sistematización de las técnicas para producir los objetos y el uso de los mismos.

Por otra parte, el estudio de la organización tecnológica como una construcción social en la que se reflejan aspectos ideológicos (Ptaffenberger, 1988) lleva a explorar el entramado de relaciones que subyace la práctica mortuoria (McHugh, 1999), de la que son parte los adornos.

El enterramiento humano distingue a la persona como ser social y a su vez expresa un orden so- cial, así como el sistema de creencias asociadas a la muerte (McHugh, 1999). En este sentido, la preparación especializada del arreglo funerario de los niños de Arazatí sugiere la consideración que tuvieron éstos para la sociedad a la que pertenecieron, ya sea por el rol que tuvieron en vida o en su muerte. Más allá de que las observaciones de los cronistas tienen un sesgo vinculado a la época y la actividades de los mismos, se encuentra una breve observación del Padre Antonio Sepp de los grupos con los que se relaciona a las riberas del río Uruguay hacia el siglo XVII, "los niños, llevan plumitas blancas en vez de hueso... esto es un signo de nobleza..." (Sepp, [1691-1733]1971:173). Y de los adultos dice "sus orejas están perforadas, pendientes... usan ciertos trozos... parecidos al nácar...” (Sepp, 1971:172). Sepp, introduce en esta discusión, el rol de los adornos (en plumas, conchas, líticos, dientes) como objetos simbólicos variables con la edad, la vida vs. la muerte de los individuos, como indicador de un rol o status, así como objetos que representan la muerte y el pasaje a otro estado (Suárez, 1998).

A su vez, la distribución regional de adornos realizados sobre $U$. haneti y otras especies de moluscos (Figura 9) podría estar indicando la existencia de un sistema simbólico compartido, así como de procesos de producción de adornos 


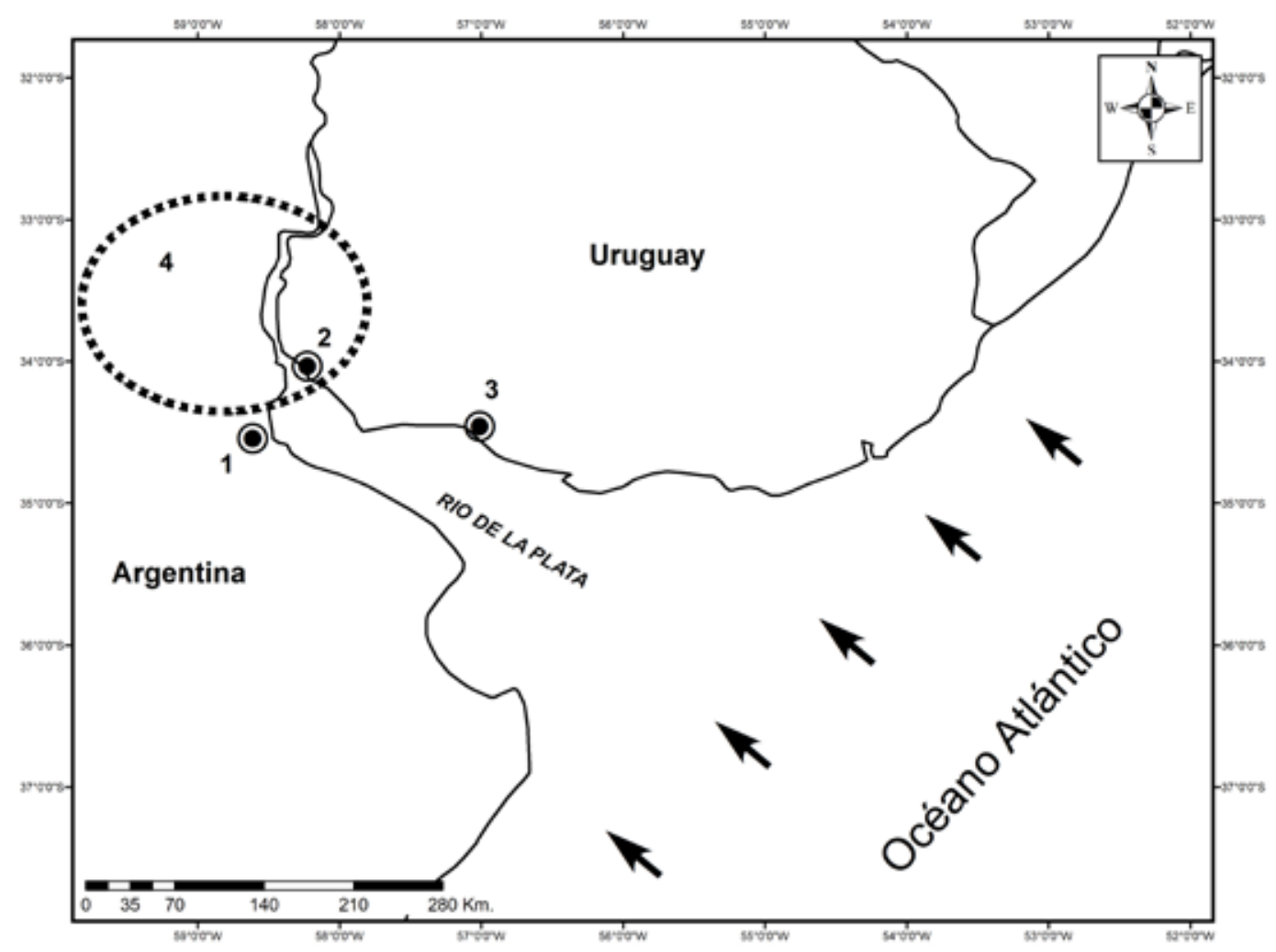

FIGURA 9

Distribución de adornos sobre Urosalpinx haneti, delta del Paraná y Río de la Plata. (1) Arroyo Sarandí, (2) Isla Martín García, (3) Arazatí, (4) Delta del Paraná. Con flechas se señalan la zona costera Atlántica y en círculo punteado el área donde se han recuperado otros adornos en $U$. haneti.

con técnicas comunes. Esta posibilidad alienta a seguir profundizando, por ejemplo, en el análisis de los medios de circulación de la información a través de redes del intercambio regional y en las vías no lingüísticas de comunicación que han sido referidas para la región (Acosta et al., 2015, 2017, Bonomo, 2007).

\section{CONCLUSIONES}

Las sociedades prehispánicas que se desarrollaron en torno al estuario del Río de la Plata hacia el Holoceno medio y tardío se describen en un largo proceso de transformaciones vinculadas a asentamientos aldeanos en relación con humedales, horticultura, integración regional, señalización del paisaje, montículos y concheros monticulares, asociadas con sociedades de rango medio (López,
2001; Iriarte, 2007; Beovide, 2013b). Se propone que para la elaboración de los pendientes automorfos en materiales conquiliológicos sobre dos materias primas distintas (Erodona mactroides y Urosalpinx haneti) confluyen técnicas comunes (desgaste por fricción y desgaste alterno) que están presentes en la región por lo menos desde hace 3000 años AP y forman parte de la especialización en la organización tecnológica de los grupos. Entre otras posibilidades, los adornos más antiguos vinculados a las sociedades formadoras de conchales se podrían asociar a la producción y uso de adornos personales (como objetos simbólicos de distintos roles en la vida cotidiana) o a la elaboración de ofrendas rituales.

Los conjuntos elaborados sobre $U$. haneti son parte de un ajuar funerario, en los que la preparación de los adornos se relaciona con un proceso complejo, en el que la obtención de la materia prima puede haber implicado distancias de más de 
$200 \mathrm{~km}$ o haber sido adquirida por intercambio. Los adornos podrían haber sido elaborados durante la ceremonia del enterramiento al tiempo de muerte, o mucho tiempo antes de que los niños fueran enterrados, siendo estos adornos parte de los bienes trasmitidos de una generación a otra como objetos simbólicos, vinculados a la vida y la muerte de los individuos. El rol que tuvieron los niños se proyecta como uno de los aspectos a seguir profundizando en el conocimiento de las sociedades previas a la conquista europea.

\section{AGRADECIMIENTOS}

El trabajo es realizado en el marco del CIRAT y del Programa Antropo-Arqueológico (D2C2MEC) con el apoyo obtenido durante los años 2013-2015 del Proyecto ANII-FCE-II-5818.

\section{REFERENCIAS}

Acosta, A.; Buc, N. \& Davrieux, N. 2015: Producción y uso de ornamentos en las tierras bajas de Sudamérica: el caso de las poblaciones humanas prehispánicas del extremo meridional de la cuenca del Plata (Argentina). MUNIBE Antropologia-Arkeologia. 66: 309-325.

Acosta, A.; Pastorino, G. \& Loponte, D. 2017: Registro de moluscos marinos entre cazadores-recolectores del norte de la región pampeana. Comechingonia. Revista de Arqueología 21: 233-261.

Álvarez, M.; Briz, I.; Balbo, A. \& Madella, M. 2011: Shell middens as archives of past environments, human dispersal and specialized resource management. Quaternary International 239: 1-7.

Andrade, T.; Botelho De Mello, E. \& Coeli, R. 1986: Analysis of molluscan remains from Ilha de Santana Site, Macaé, Brasil. Journal of Field Archaeology 13: 83-97.

Beovide, L. 2008: Conductas marisqueadoras y procesos tafonómicos: explorando el registro arqueomalacológico Platense, Resúmenes 1 Congreso Nacional de Zooarqueología Argentina 7.

- 2011: Arqueozoología de los depósitos conchilíferos de la cuenca inferior del río Santa Lucía. Tesis doctoral, PEDECIBA, Universidad de la República, Uruguay. Ms.

- 2013a: Concheros en la costa uruguaya del Río de la Plata: una aproximación a la explotación y uso de moluscos por las sociedades de fines del Holoceno medio. Cuadernos del Instituto Nacional de Antropología y Pensamiento Latinoamericano, Series Especiales 1(1): 135-149.

- 2013b: Las sociedades prehistóricas de la cuenca del río Santa Lucía: una mirada desde la Epistemología de la Complejidad, Cuadernos del Instituto Nacional de Antropología y Pensamiento Latinoamericano, Series Especiales 1(4): 81-95.

- 2014: Shell middens and the use of molluscs in the Late Middle Holocene in the Rio de La Plata: an ethnoarchaeological contribution. Archaeomalacology: Shells in the Archaeological Record: 111-121. B.A.R. (International Series). Oxford.

Beovide, L. \& Campos, S. 2014: Interacciones entre las sociedades y las plantas durante el Holoceno medio-tardío en el área septentrional del Río de la Plata. Revista Española de Antropología Americana 44(2): 574-602.

Beovide, L. \& Lorenzo, M. 2011: Huellas antrópicas y naturales en el material arqueomalacológico platense. In: Vega-Centeno, R.; Olivera, P. \& Petrick, S. (eds.): II Congreso Latinoamericano de Arqueometría 1: 307-321. Lima.

- 2014: Caracterización de tres tipos de adornos en valvas de moluscos en la prehistoria del Río de la Plata: huellas de las técnicas de producción. Libro de Resúmenes del IV Congreso Latinoamericano de Arqueometría: 81-82. México.

Beovide, L. \& Martínez, M. 2014: Concheros Arqueológicos en la Costa Uruguaya: Revisión y Perspectivas. Revista Chilena de Antropología 29: 26-32.

Beovide, L.; Pardo, H.; Faccio, R.; Figueiro, G.; Martínez, S.; Baeza. J. \& Lorenzo, M. 2014: Los niños prehispánicos de Arazatí y su ajuar funerario. Libro del IV Congreso Latinoamericano de Arqueometría: 277-278. México.

Beovide,L.;Martínez,S.\&Figueiro,G. 2015a:Urosalpinx haneti (gasterópoda) como adorno funerario ( ca. 900 a 500 años AP), Arazatí, costa del Río de la Plata (Uruguay). Resúmenes III Congreso Latinoamericano de Zooarqueología.

http://www.octeventos.com/elaz/es/.

Beovide, L.; Martínez, S. \& Norbis, W. 2015b: Discriminación entre acumulaciones de moluscos naturales, antrópicas modernas y arqueológicas, constituidas por las mismas especies. Cuadernos del Instituto $\mathrm{Na}$ cional de Antropología y Pensamiento Latinoamericano-Series Especiales 2(4): 21-37.

- 2017: Space Use Patterns and Resource exploitation of Shell Middens from the Río De La Plata Coast ( $\mathrm{Ca}$. 6,000 to 2,000 Year BP), Uruguay. Zooarchaeology 
in the Neotropics Environmental Diversity and $\mathrm{Hu}$ man-Animal Interactions: 81-103.

Bonino, V. 1961: Los primitivos habitantes del Uruguay, y el uso de los moluscos en su economía, en su decoración y en sus ritos. Comunicaciones de la Sociedad Malacología del Uruguay 1: 11-14.

Bonomo, M. 2005: Costeando las llanuras. Arqueología del litoral marítimo pampeano. Sociedad Argentina de Antropología, Colección Tesis Doctorales, Buenos Aires.

- 2007: El uso de moluscos marinos por los cazadores recolectores pampeanos. Chungara 9(1): 87-102.

Bracco, R.; Panario, D. \& Ures, C. 1999: Dataciones de ${ }^{14} \mathrm{C}$ y efecto de reservorio para el litoral del Uruguay. I Jornadas del Cenozoico del Uruguay. Facultad de Ciencias, Montevideo: 4-5.

CARCElles, A. 1941: Erodona mactroides en el río de la Plata. Physis 19: 11-21.

Cimino, A. 2007: Arqueomalacología en las Sierras de la Vida: Análisis de los adornos realizados sobre materia prima malacológica hallados en el sitio Chenque I (P.N.L.C., Provincia de la Pampa). Arqueología en las Pampas 1: 309-324.

Claassen, C. 1998: Shells. Cambridge Manuals in Archaeology Series. Cambridge, New York.

Clark, J. \& PARry, W. 1990: Craft specialization and cultural complexity. Research in Economic Anthropology: a Research Annual 12: 289-346.

Costa, F.H.A. 1993: Urosalpinx haneti, a south-western Atlantic Ocenebrinaere described. Conchiglia 25: $57-$ 62.

DA Costa, M.B. 1971: Importância paleoecológica e estratigráfica de Erodona mactroides Daudin (Mollusca, Bivalvia). Iheringia (Serie Geologia) (4): 3-18.

Feinman, G. \& Neitzel, J. 1984: Too Many Types: An Overview of Sedentary Prestate Societies in the Americas. Advances in Archaeological Method and Theory 7: 39-102.

Gandara, M. 1990: La Analogía Etnográfica como Heurística: Lógica muestra, Dominios Ontológicos e Historicidad. In: Sugiura, Y. \& Serra, M. (eds.): Etnoarqueología: primer Coloquio Bosch-Gimpera: 44-84. UNAM, México.

GASPAR, M. 1998: Considerations of the sambaquis of the Brazilian coast. Antiquity 72: 592-615.

Gaspar, M. \& De Blasis, P. 2006: Balance de las Investigaciones Arqueológicas en Sambaquis. Problemáticas de la Arqueología Contemporánea 1: 281-283.

Gusinde, M. 1987 [1937]: Los yámana. Los indios de Tierra del Fuego: Resultados de mis cuatro expediciones en los años 1918 hasta 1924, organizadas bajos los auspicios del Ministerio de Instrucción Pública de Chile, II: 1. Centro Argentino de Etnología Americana, Buenos Aires.

IRIARTE, J. 2007: La construcción social y transformación de las comunidades del Periodo Formativo temprano del sureste de Uruguay. Boletín de Arqueología PUCP. 11: 143-166.

LeOnardT, S. 2014: Producción local de cuentas de valva en el bosque del Noroeste de Patagonia. Una aproximación desde la arqueología experimental. Relaciones de la Sociedad Argentina de Antropología 39(2): 463-482.

LóPEZ, J. 2001: Las Estructuras Tumulares (Cerritos) del Litoral Atlántico Uruguayo. Latin American Antiquity 12(3): 231-255.

Lothrop, S. 1932: Indians of the Paraná Delta River. Annals of the New York. Academy of Sciences XXXII: 77-232.

McHugh, F. 1999: Theoretical and Quantitative Approaches to the Study of Mortuary Practice. B.A.R. (International Series) 785. Oxford.

MaÑosA, C. 1995: Utilización prehistórica de moluscos en Punta de la Coronilla (Rocha, Uruguay). Arqueología en el Uruguay 113-122.

Martínez, S. \& Rojas, A. 2013: Relative sea level during the Holocene in Uruguay. Palaeogeography, Palaeoclimatology, Palaeoecology 374: 123-131.

Martínez, S.; Rojas, A.; Ubilla, M.; Verde, M.; Perea, D. \& PiñEIRO, G. 2006: Molluscan assemblages from the marine Holocene of Uruguay: composition, geochronology and paleoenvironmental signals. Ameghiniana 43(2): 385-398.

Nelson, M. 1991: The study of technological organization. Archeological Method and Theory 3: 57-100.

PAZ, C. 2010: Estudio de las vestimentas de concha del templo de la Serpiente Emplumada de Teotihuacan. In: Suárez Díez, L. \& Velázquez Castro, A. (eds.): Ecos del Pasado: los moluscos arqueológicos de México: 153-181. Instituto Nacional de Antropología e Historia (Colección Científica 572), México.

Penino, R. 1957: Algunos informes sobre Antropología indígena del Uruguay. La Nación Charrúa 294-297.

Pfaffenberger, B. 1998: Fetishised Objects and Humanised Nature: Towards an Anthropology of Technology. Man 23(2): 236-252.

Rios, E.C. 1994: Seashells of Brazil. Museu Oceanográfico da Fundação Universidade do Rio Grande. 329 pp.

RogGe, J. 2005: Fenómenos da frontera: um estudo das situaçoes de contato entre os portadores das tradiçoes cerámicas pré-historicas no Río Grande do Sul. Pesquisas, Antropología 62: 7-125. 
RosA, M. 2011-2012: Moluscos y conchillas. Una mirada bajo la lupa, del material malacológico recuperado por la Misión de Rescate Arqueológico de Salto Grande. Anuario de Arqueología 207-242.

Scarabino, F.; Zaffaroni, J.C.; Carranza, A.; Clavijo, C. \& NIN, M. 2006a: Gasterópodos marinos y estuarinos de la costa uruguaya: faunística, distribución, taxonomía y conservación. Bases para el manejo y la conservación de la costa uruguaya: 143-155.

- 2006b: Bivalvos marinos y estuarinos de la costa uruguaya: faunística, distribución, taxonomía y conservación. Bases para el manejo y la conservación de la costa uruguaya: 157-169.

SEIJo, C. 1930: Cráneo con fragmentos de un collar. $R e$ vista Sociedad Amigos de la Arqueología 4: 183-195.

Sepr, A. 1971: Relación de Viaje a las Misiones Jesuíticas (1691-1733). Editorial Universitaria, Buenos Aires.

SuÁreZ, L. 1974: Técnicas prehispánicas en los objetos de concha. Colección Científica, Arqueología $N^{\circ} 14$. Instituto Nacional de Arqueología e Historia, México.

- 1977: Tipología de los objetos prehispánicos de concha. Colección Científica, Arqueología No 54. Instituto Nacional de Arqueología e Historia, México.

- 1998: Los estudios arqueológicos de la concha. La antropología en México 6. El desarrollo técnico.

SuÁREZ, R. 2017: The human colonization of the Southeast Plains of South America: Climatic conditions, technological innovations and the peopling of Uru- guay and south of Brazil. Quaternary International 431: 181-193.

Trubbit, M.B. 2003: The Production and Exchange of Marine Shell Prestige Goods. Journal of Archaeological Research 11(3): 243-277.

Vargas, A.I.; Toledo, M.; Molina, L. \& Montcourt, C. 1993: Los artífices de la concha. Serie Contribuciones a la arqueología tropical 1, USDA Forest Southern Region \& Organización de los Estados Americanos. Estado de Sucre, Venezuela.

VelázQuez, A. 2007: La producción especializada de los objetos de concha del Templo Mayor de Tenochtitlan. Colección Científica, Antropología. INAH, México.

- 2010: Arqueología experimental en conchas de moluscos. In: Suárez Díez, L. \& Velázquez Castro, A. (eds.): Ecos del Pasado: los moluscos arqueológicos de México: 67-78. Colección Científica 572. Instituto Nacional de Antropología e Historia, México.

Velázquez, A.; Melgar, T. \& Hocquenghem, A. 2006: Análisis de las huellas de manufactura del material malacológico de Tumbes, Perú. Bulletin de l'Institut français d'études andines: 21-35.

Villarmarzo, E. 2009: Estudio Experimental sobre valvas de Berberechos (Donax hanleyanus). La arqueología como profesión: los primeros 30 años: 745-754.

- 2010: Arqueomalacología del sitio La Esmeralda (Rocha, Uruguay). Comunicaciones de la Sociedad Malacológica del Uruguay 9(93): 215-230. 